\title{
World Congress of Nurse Anaesthetists Congress 2012
}

\author{
Manda Dunne \\ IFNA Country Representative, UK
}

Dear BARNA members,

$\mathrm{P}$ lease take time to visit the WCNA 2012 web page. The International Federation of Nurse Anaesthetists Congress is being held in the beautiful town of Ljubljana, Slovenia, this year, between May 26 and 29, 2012.

I would encourage you to try to attend if at all possible. I appreciate that funds are difficult to come by these days, but I cannot express to you how rewarding this Congress is and what an experience can be had!

The networking opportunities are superb, not to mention the excellent education/scientific programme that is being offered. There are many hands on workshops, which are very interesting and very satisfying when you achieve the outcome!

There will be a commercial exhibition supported by many of the anaesthetic companies you deal with in the United Kingdom, plus many others, which will probably be new and exciting to you.

I hope you share my enthusiasm for this Congress and manage to find the funds to attend. Even if you have to beg, steal or borrow, try to be there!! You are guaranteed a very warm welcome.

Please visit www.wcna2012.com for more information and registration. 